\title{
DETERMINAN KESIAPSIAGAAN SISWA DALAM IMPLEMENTASI PENGURANGAN RISIKO BENCANA MELALUI PENDIDIKAN FORMAL DI SMAN UNGGUL SIGLI KECAMATAN PIDIE
}

\author{
Cut Wardah $^{1}$, Donal Nababan ${ }^{2}$, Mido Ester. J. Sitorus ${ }^{3}$, Elsarika Damanik ${ }^{4}$ \\ Magister Kesehatan Masyarakat ${ }^{1,2}$, S1 Kesehatan Masyarakat ${ }^{3,}$ D3 Kebidanan ${ }^{4}$ \\ Universitas Sari Mutiara Indonesia \\ cutwardah75@gmail.com¹, mido71torus@yahoo.com³
}

\begin{abstract}
Indonesia is an archipelago. Geographically, it is located in a series of tectonic plates from Australia, the Eurasia Pacific and the Philippines, which makes Indonesia vulnerable to geographical changes. Therefore, Indonesia is one of the countries prone to disasters including earthquakes and tsunamis. This study aims to analyze the relationship between knowledge and attitude variables, emergency response plans, early warning systems, and mobility of resources on student preparedness in implementing disaster risk reduction through formal education in senior secondary schools. This study used an analytical study method with a cross sectional design. The population in this study were 140 students at SMA Negeri Unggul Sigli using Stratified Random Sampling. This research was conducted in October - December 2020. Univariate, bivariate and multivariate data analysis with Chi-square test and Logistic Regression test. There is a significant relationship between Knowledge and attitude variables with ( $p$ value 0.022); Emergency response plan with ( $p$ value 0.002); Early warning system with ( $p$. Value <0.001); and resource mobility ( $p$ value 0.006). about students' preparedness in implementing disaster risk reduction ( $p \leq 0.05)$. The results of multivariate analysis with multiple logistic regression tests obtained variables that had a significant effect on student preparedness in implementing disaster risk reduction (DRR), namely: variable resource mobility with a coefficient of B. 0.512 and $\operatorname{Exp}(B)$ of 5, 99. getting mobility resources properly has a greater chance of being ready to implement disaster risk reduction 5.99 compared to students who do not get it. From this study, it was found that there was a significant influence on the preparedness of students in implementing DRR, namely the variable of resource mobility.
\end{abstract}

Keywords $\quad$ : Student Preparedness, Implementation Of Disaster Risk Reduction, Formal Education

\begin{abstract}
ABSTRAK
Indonesia merupakan negara kepulauan secara Geografis terletak di rangkaian lempeng tektonik Australia, Eurasia Pasifik dan Filipina yang membuat Indonesia rentan terhadap perubahan geografis. Oleh karena itu, Indonesia menjadi salah satu negara yang rawan bencana termasuk gempa bumi dan tsunami. Penelitian ini bertujuan untuk menganalisis hubungan antara variabel pengetahuan dan sikap, rencana tanggap darurat, sistem peringatan dini, dan mobilitas sumber daya terhadap kesiapsiagaan siswa dalam melaksanakan pengurangan risiko bencana melalui pendidikan formal di sekolah menengah atas. Penelitian menggunakan metode studi analitik dengan desain cross sectional. Populasi dalam penelitian ini adalah 140 siswa di SMA Negeri Unggul Sigli dengan menggunakan Stratified Random Sampling. Penelitian ini dilaksanakan pada bulan Oktober - Desember 2020. Analisis data univariat, bivariat dan multivariat dengan uji Chi-square dan uji Regresi Logistik. Terdapat hubungan yang signifikan antara variabel Pengetahuan dan sikap dengan (nilai $\mathrm{p} 0,022$ ); Rencana tanggap darurat dengan (nilai p 0,002); Sistem peringatan dini dengan ( $\mathrm{p}$. Value <0,001); dan mobilitas sumber daya (nilai $\mathrm{p} 0,006$ ). tentang kesiapsiagaan siswa dalam melaksanakan pengurangan risiko bencana $(p \leq 0,05)$. Hasil analisis multivariat dengan uji regresi logistik ganda diperoleh variabel yang berpengaruh signifikan terhadap kesiapsiagaan siswa dalam melaksanakan pengurangan risiko bencana (PRB), yaitu: variabel mobilitas sumber daya dengan koefisien B. 0,512 dan Exp (B) sebesar 5, 99. Artinya, siswa yang mendapatkan resource mobilitas dengan baik memiliki peluang lebih besar untuk siap melaksanakan pengurangan risiko bencana 5,99 dibandingkan siswa yang tidak
\end{abstract}


mendapatkan. Dari penelitian ini didapatkan bahwa terdapat pengaruh yang signifikan terhadap kesiapsiagaan siswa dalam melaksanakan PRB yaitu variabel mobiltas sumber daya.

Kata Kunci : Kesiapsiagaan Siswa, Implementasi Pengurangan Risiko Bencana, Pendidikan Formal

\section{PENDAHULUAN}

Indonesia merupakan negara kepulauan yang terdiri dari 17.508 pulau, dan terletak di antara Samudra Pasifik dan Samudra Hindia. Secara geografis terletak dirangkaian lempeng tektonil Australia, Pasifik Eurasia dan Filipina yang membuat Indonesia menjadi rentan terhadap perubahan geografis (Kemendikbud, 2015)

Iklim Indonesia sangat dipengaruhi oleh lokasi dan karakteristik geografis. Membentang di $6.400 \mathrm{~km}$ antara Samudra Pasifik dan Samudra Hindia yang memiliki 3 pola iklim dasar; monsunal, khatulistiwa, dan sistem iklim lokal. Hal ini menyebabkan perbedaan dramatis dalam pola curah hujan di Indonesia, karena posisi dan lokasinya yang berada disalah satu daerah bencana paling aktif di dunia dan rawan bencana (Kemendikbud, 2015)

Indonesia salah satu negara yang memiliki wilayah yang rentan terhadap bencana termasuk gempa dan tsunami. Salah satu dampak dari gempa dan tsunami yang terjadi di Indonesia adalah kerusakan sarana dan prasarana bangunan, termasuk bangunan sekolah, yang mengakibatkan terganggunya proses pembelajaran siswa di sekolah. Lebih dari 7.000 sekolah rusak berat akibat gempa dan tsunami sejak tahun 2004 (Kemendikbut, 2015).

Berdasarkan Data Badan Nasional Penanggulangan Bencana (2017) menyatakan bahwa dalam 15 tahun terakhir (2002 - 2016), jumlah kejadian bencana di Indonesia meningkat hampir 20 kali lipat. Lebih dari $90 \%$ kejadian bencana di Indonesia diakibatkan oleh banjir dan tanah longsor, lebih dari 28 juta orang terkena dampak. Namun, berdasarkan jumlah korban jiwa, bencana terkait geologi adalah jenis bencana yang paling mematikan, dimana lebih dari $90 \%$ korban meninggal dunia dan hilang akibat bencana disebabkan oleh gempa bumi dan tsunami. Bencana Kejadian tsunami paling besar terjadi pada tahun 2018, kejadian bencana tsunami meningkat dari tahun 2012 sampai 2018. (Dewi,2019)

Bencana merupakan segala kejadian yang menyebabkan kerusakan lingkungan, gangguan geologis, hilangnya nyawa manusia atau memburuknya derajat kesehatan ataupun pelayanan kesehatan skala tertentu, serta akan memberikan dampak yang cukup besar bagi intervensi program kemanusian dan program pengembangan dan akan terus memberikan tantangan bagi pengembangan dan penyelenggaraan sektor pendidikan. (Dewi,2019)

Badan Nasional Penanggulangan Bencana (BNPB) mencatat terjadi 2.271 kejadian bencana dari awal tahun 2017 hingga 19 Desember 2017, dimana 93 persen kejadian merupakan bencana hidrometeorologi, puting beliung, longsor dan banjir. Jika merujuk pada kajian yang dilakukan oleh BNPB, jutaan masyarakat Indonesia berada dalam ancaman bahaya bencana alam (BNPB, 2017).

Berdasarkan data dari BNPB Nasional (2020) terdapat jumlah kejadian bencana alam sebanyak 1.115 kejadian. dimana kejadian yang mendominasi adalah bencana banjir diikuti puting beliung dan tanah lonsor. Sedangka dampak bencana periode 1 januari sampai dengan 18 April 2020 sebagai berikut: meninggal 151 jiwa. hilang 5 jiwa, 1.818 .738 jiwa menderita dan mengunsi dan 229 jiwa luka-luka. Dampak kerusakan rumah rusak 16.495 dan fasilitas rusak 669. Jumlah kejadian perjenis bencana, dimana, gempa bumi 4, erupsi gunung api 3, kekeringan 1, banjir 409, tanah lonsor 250, puting beliung 331 .

Berdasarkan catatan sejarah, Aceh pernah mengalami 4 kali bencana Tsunami, 
yaitu pada tahun 1797, 1891, 1907 dan 2004. Bencana banjir juga melanda hampir seluruh wilayah Aceh. Setidaknya ada 3 bencana letusan gunung api dalam periode 1815 hingga Juni 2017 pada gunung api aktif type A, yaitu Gunung Peut Sagoe, Gunung Seulawah Agam dan Gunung Burni Telong (BNPB, 2017).

Pada Raqan Aceh mengenai pendidikan kebencanaan (2019) menyatakan Aceh merupakan salah satu provinsi di Indonesia yang rawan bencana, karena Aceh berada dalam kawasan "ring of fire". Secara seismisitas wilayah Aceh rawan bencana gempa bumi. Aceh kembali mendapatkan cobaan Gempa yang berpusat di 18 kilometer timur laut Pidie pada Rabu Desember 2016. Para ahli menduga gempa ini disebabkan oleh sesar Samalanga Sipopok. Di luar ketidakpastian itu, gempa ini memberi gambaran bahwa Aceh pun bisa terus dilanda gempa dengan mekanisme sesar mendatar serta berpusat pada kedalaman yang dangkal (BPBA, 2019).

Banyaknya korban pada setiap bencana dapat dielimininasi dengan cara menumbuhkan kesadaran masyarakat tentang kebencanaan, hal penting yang perlu dilakukan adalah mendidik masyarakat untuk memiliki pengetahuan tentang kebencanaan. Lembaga pendidikan memiliki tanggung jawab/mengintrusi pengetahuan kebencanaan dalam kurikulum pendidikan pada setiap jalur, jenjang, dan jenis pendidikan (BPBA, 2019).

Badan Penanggulangan Bencana Aceh mencatat dimana 1290 kejadian bencana di Aceh sejak Januari hingga Maret 2020 antara lain kebakaran pemukiman yakni sebanyak 94 kali dimana terjadi peningkatan dibandingkan dengan tahun 2019. Terjadinya kebakaran hutan dan lahan yakni sebanyak 156 kali, hampir 5 kali lipat dari tahun sebelumnya, diperiode yang sama yakni terjadi $27 \mathrm{kali}$, angin puting beliung terjadi sebanyak 17 kali, gempa bumi terjadi 5 kali dengan magnitude yang berkisar antara 5,1-5,5 SR dan semua bencana juga berdampak pada sarana pendidikan (BPBA, 2020).

Berdasarkan data BPBD (2019) Kabupaten Pidie, kejadian bencana yang pernah terjadi sebagai berikut: bencana banjir terjadi pada tanggal 10 Maret 2011 dengan 2 kejadian dalam hari yang sama mengakibatkan 24 jiwa meninggal 622 rumah rusak berat dan 684 rusak ringan, bencana banjir dan tanah lonsor dengan 1 kali kejadian terjadi pada tanggal 26 januari 2007 yang mengakibatkan 38.809 jiwa mengunsi, bencana gempa bumi terbesar terjadi pada tanggal 2 November 2000 yang mengkibatkan 4 jiwa meninggal dan 254 jiwa luka-luka dan 802 rumah rusak berat, bencana gempa bumi dan tsunami terjadi sebanyak 2 kali kejadian pada hari yang sama kejadian pada tanggal 26 Desember 2004 mengakibatkan 9,292 jiwa meninggal, 2.925 jiwa hilang, 62.156 mengunsi.

Kabupaten Pidie terdiri dari 23 Kecamatan, dimana 7 wilayah Kecamatan $(30,4 \%)$ diantaranya berada di pesisir pantai yang merupakan daerah yang rawan bencana alam seperti gempa/stunami, angin puting beliung dan banjir.

Berdasarkan BPBD Pidie (2020) wilayah SMA Negeri Unggul Sigli kecamatan Leubue, Kabupaten Pidie yang berada di daerah pesisir pantai yang pernah mengalami gempa/stunami pada tanggal 26 Desember tahun 2004, dimana merupakan salah satu wilayah yang rawan dan waspada bencana yang ditetapkan oleh BPBD Aceh.

Dari survey awal yang dilakukan serta keterangan dari pimpinan sekolah dan tenaga pendidik, dimana akhir-akhir ini frekuensi dan intensitas kedahsyatan gempa bumi, banjir, angin puting beliung kita rasakan semakin meningkat sejak dalam 10 tahun terakhir. Oleh karena itu pemahaman gejala terjadinya bencana perlu ditingkatkan dan disikapi dengan tepat, kesalahan bersikap dalam menghadapi bencana perlu dihindari. Penerapan kesiapsiagaan bencana di sekolah ini harus diajarkan kepada siswa sedini mungkin terutama siswa SMA karena mereka mudah 
mengerti apa yang dijelaskan dan dapat menerapkannya apabila sewaktu-waktu terjadi bencana. Dan penelitian ini dilakukan pada SMA Negeri Unggul Pidie karena kawasannya yang terletak dipesisir pantai yang rawan akan bencana.

Berdasarkan permasalahan di atas maka peneliti tetarik untuk melakukan penelitian tentang "Determinan kesiapsiagaan siswa dalam implementasi pengurangan risiko bencana melalui pendidikan formal di SMA Negeri Unggul Sigli Kec. Pidie Kab. Pidie tahun 2020. Penelitian ini bertujuan untuk mengetahui faktor yang mempengaruhi kesiapsiagaan siswa dalam melaksanakan pengurangan risiko bencana melalui pendidikan formal di sekolah.

\section{METODE}

Jenis penelitian analitik dengan desain cross sectional, peneliti mencari hubungan antara variabel bebas (risiko) dengan variabel tergantung (efek) dengan melakukan pengukuran sesaat, desain cross sectional tidak ada prosedur tindak lanjut atau follow-up (Sastroasmoro, 2016). Penelitian ini dilakukan di SMA Negeri
Unggul Sigli Kecamatan Pidie Kabupaten Pidie tahun 2020. Penelitian ini dilaksanakan pada bulan Oktober Desember Tahun 2020 di SMA Negeri Unggul Sigli Kecamatan Pidie Kabupaten Pidie Provinsi Aceh. Populasi dalam penelitian ini adalah seluruh siswa di SMA Negeri Unggul Sigli Kecamatan Pidie sebanyak 140 siswa. Sampel diambil sebagian dari populasi menggunakan Stratified Random Sampling. Dan ditemukan sampel minimal adalah 104 responden.

Pengumpulan data dilakukan dengan dua cara yaitu data primer dan data sekunder. Data primer diperoleh melalui observasi dan wawancara langsung dengan responden menggunakan kuesioner. Data sekunder diperoleh melalui instansi pemerintah serta intansi terkait lainnya.Pengolahan Data pada penelitian ini adalah data yang sudah terkumpul melalui kuesioner dilakukan pengolahan data untuk diproses (Handini. 2018), melalui kegiatan sebagai berikut : Editing, Coding, Cleaning, Tabulatimg. Dan dilakukan Analisis data univariat, bivariat dan multivariat menggunakan uji Chi-square dan uji Regresi Logistik

\section{HASIL}

Tabel 1. Hubungan Pengetahuan dan Sikap Terhadap Kesiapsiagaan Siswa Dalam Implementasi PRB di SMA Negeri Unggul Sigli Kecamatan Pidie Kabupaten Pidie Tahun 2020

\begin{tabular}{|c|c|c|c|c|c|c|c|}
\hline \multirow{3}{*}{$\begin{array}{c}\text { Pengetahuan } \\
\text { dan } \\
\text { Sikap }\end{array}$} & \multicolumn{4}{|c|}{$\begin{array}{c}\text { Kesiapsiagaan Siswa Dalam } \\
\text { Implementasi PRB }\end{array}$} & \multirow{2}{*}{\multicolumn{2}{|c|}{ Jumlah }} & \multirow{3}{*}{$\begin{array}{c}p \\
\text { value }\end{array}$} \\
\hline & \multicolumn{2}{|c|}{ Siap } & \multicolumn{2}{|c|}{ Tidak Siap } & & & \\
\hline & $\mathbf{N}$ & $\%$ & $\mathrm{n}$ & $\%$ & $\mathbf{n}$ & $\%$ & \\
\hline Baik & 40 & 58,0 & 29 & 42,0 & 69 & 100 & \multirow{3}{*}{0.022} \\
\hline Kurang & 12 & 34,3 & 23 & 65,7 & 35 & 100 & \\
\hline Total & 52 & 50,0 & 52 & 50,0 & 104 & 100 & \\
\hline
\end{tabular}

Sumber: Data primer Tahun 2020

Berdasarkan tabel 1. diiketahui bahwa dari 104 reponden dengan proporsi pengetahuan dan sikap baik yaitu 69 responden, dimana pada umumnya yaitu
$58,0 \%$ responden siap dalam implementasi pengurangan resiko bencana (PRB) dan 29 responden $(42,0 \%)$ diantaranya tidak siap dalam implementasi pengurangan risiko 
bencana (PRB). Sedangkan proporsi pengetahuan dan sikap kurang yaitu 35 responden, dimana pada umumnya $65,7 \%$ tidak siap dalam implementasi pengurangan risiko bencana (PRB) dan 12 responden $(34,3 \%)$ diantaranya siap dalam implementasi pengurangan risiko bencana (PRB)
Hasil uji Chi-sguare menunjukkan $p$ value sebesar 0.022 pada tingkat kemaknaan $5 \%$ ada hubungan yang significance antara pengetahuan dan sikap terhadap kesiapsiagaan siswa dalam implementasi pengurangan risiko bencana (PRB) melalui pendidikan formal di SMA Negeri Unggul sigli dimana ( $p$ value $\leq$ $0,05)$.

Tabel 2. Hubungan Rencana Tanggap Darurat Terhadap Kesiapsiagaan Siswa Dalam Implementasi PRB di SMA Negeri Unggul Sigli Kecamatan Pidie Kabupaten Pidie Tahun 2020

\begin{tabular}{|c|c|c|c|c|c|c|c|}
\hline \multirow{3}{*}{$\begin{array}{c}\text { Rencana Tanggap } \\
\text { Darurat }\end{array}$} & \multicolumn{4}{|c|}{$\begin{array}{c}\text { Kesiapsiagaan Siswa } \\
\text { Dalam Implementasi PRB }\end{array}$} & \multirow{2}{*}{\multicolumn{2}{|c|}{ Jumlah }} & \multirow{2}{*}{$\underset{\text { value }}{p}$} \\
\hline & \multicolumn{2}{|c|}{ Siap } & \multicolumn{2}{|c|}{ Tidak Siap } & & & \\
\hline & $\mathbf{N}$ & $\%$ & $\mathbf{n}$ & $\%$ & $\mathbf{N}$ & $\%$ & \multirow{4}{*}{0.002} \\
\hline Baik & 26 & 70,3 & 11 & 29,7 & 37 & 100 & \\
\hline Tidak Baik & 26 & 38,8 & 41 & 61,2 & 67 & 100 & \\
\hline Total & 52 & $\mathbf{5 0 , 0}$ & 52 & $\mathbf{5 0 , 0}$ & 104 & 100 & \\
\hline
\end{tabular}

Sumber: Data primer Tahun 2020

Berdasarkan tabel 2. diketahui bahwa dari 104 reponden dengan proporsi rencana tanggap darurat baik yaitu 37 responden, dimana pada umumnya yaitu $70,3 \%$ responden siap dalam implementasi pengurangan risiko bencana (PRB) dan 11 responden $(29,7 \%)$ diantaranya tidak siap dalam implementasi pengurangan risiko bencana (PRB). Sedangkan proporsi rencana tanggap darurat tidak baik yaitu 67 responden, dimana pada umumnya $61,2 \%$ tidak siap dalam implementasi pengurangan resiko bencana (PRB) dan 26 responden

$(38,8 \%)$ diantaranya siap dalam implementasi pengurangan risiko bencana (PRB).

Hasil uji Chi-sguare menunjukkan $p$ value sebesar 0.002 pada tingkat kemaknaan 5\% ada hubungan yang significance antara rencana tanggap darurat terhadap kesiapsiagaan siswa dalam implementasi pengurangan risiko bencana (PRB) melalui pendidikan formal di SMA Negeri Unggul sigli dimana ( $p$ value $\leq$ $0,05)$.

Tabel 3. Hubunga Sistim Peringatan Dini Terhadap Kesiapsiagaan Siswa Dalam Implementasi PRB di SMA Negeri Unggul Sigli Kecamatan Pidie Kabupaten Pidie Tahun 2020

\begin{tabular}{|c|c|c|c|c|c|c|c|}
\hline \multirow{3}{*}{$\begin{array}{c}\text { Sistim Peringatan } \\
\text { Dini }\end{array}$} & \multicolumn{4}{|c|}{$\begin{array}{c}\text { Kesiapsiagaan Siswa } \\
\text { Dalam Implementasi PRB }\end{array}$} & \multirow{2}{*}{\multicolumn{2}{|c|}{ Jumlah }} & \multirow{3}{*}{$\begin{array}{c}p \\
\text { value }\end{array}$} \\
\hline & \multicolumn{2}{|c|}{ Siap } & \multicolumn{2}{|c|}{ Tidak Siap } & & & \\
\hline & $\mathbf{N}$ & $\%$ & $\mathbf{n}$ & $\%$ & $\mathbf{N}$ & $\%$ & \\
\hline Baik & 34 & 70,8 & 14 & 29,2 & 48 & 100 & \multirow{3}{*}{0.000} \\
\hline Tidak Baik & 18 & 32,1 & 38 & 67,9 & 56 & 100 & \\
\hline Total & 52 & 50,0 & 52 & $\mathbf{5 0 , 0}$ & 104 & 100 & \\
\hline
\end{tabular}

Sumber: Data primer Tahun 2020

Berdasarkan tabel 3. diketahui bahwa dari 104 reponden dengan proporsi sistim

peringatan dini baik yaitu 48 responden, dimana pada umumnya yaitu $70,8 \%$ 
responden siap dalam implementasi pengurangan risiko bencana (PRB) dan 14 responden $(29,2 \%)$ diantaranya tidak siap dalam implementasi pengurangan resiko bencana (PRB). Sedangkan proporsi sistim peringatan dini tidak baik yaitu 56 responden, dimana pada umumnya $67,9 \%$ tidak siap dalam implementasi pengurangan risiko bencana (PRB) dan 18 responden $(32,1 \%)$ diantaranya siap dalam implementasi pengurangan risiko bencana (PRB)

Hasil uji Chi-sguare menunjukkan $p$ value sebesar 0.000 pada tingkat kemaknaan $5 \%$ ada hubungan yang significance antara sistim peringatan dini terhadap kesiapsiagaan siswa dalam implementasi pengurangan risiko bencana (PRB) melalui pendidikan formal di SMA Negeri Unggul sigli dimana ( $p$ value $\leq$ $0,05)$.

Tabel 4. Hubungan Mobilitas Sumber Daya Terhadap Kesiapsiagaan Siswa Dalam Implementasi PRB di SMA Negeri Unggul Sigli Kecamatan Pidie Kabupaten Pidie Tahun 2020

\begin{tabular}{|c|c|c|c|c|c|c|c|}
\hline \multirow{3}{*}{$\begin{array}{l}\text { Mobilitas } \\
\text { Sumber Daya }\end{array}$} & \multicolumn{4}{|c|}{$\begin{array}{l}\text { Kesiapsiagaan Siswa Dalam } \\
\text { Implementasi PRB }\end{array}$} & \multirow{2}{*}{\multicolumn{2}{|c|}{ Jumlah }} & \multirow{2}{*}{$\begin{array}{c}p \\
\text { value }\end{array}$} \\
\hline & \multicolumn{2}{|c|}{ Siap } & \multicolumn{2}{|c|}{ Tidak Siap } & & & \\
\hline & $\mathbf{N}$ & $\%$ & $\mathbf{N}$ & $\%$ & $\mathbf{N}$ & $\%$ & \multirow{4}{*}{0.006} \\
\hline Baik & 30 & 65,2 & 16 & 34,8 & 46 & 100 & \\
\hline Tidak Baik & 22 & 37,9 & 36 & 62,1 & 58 & 100 & \\
\hline Total & 52 & 50,0 & 52 & 50,0 & 104 & 100 & \\
\hline
\end{tabular}

Sumber: Data primer Tahun 2020

Berdasarkan tabel 4. diketahui bahwa dari 104 reponden dengan proporsi mobilitas sumber daya baik yaitu 46 responden, dimana pada umumnya yaitu $65,2 \%$ responden siap dalam implementasi pengurangan risiko bencana (PRB) dan 16 responden $(34,8 \%)$ diantaranya tidak siap dalam implementasi pengurangan resiko bencana (PRB). Sedangkan proporsi mobilitas sumber daya tidak baik yaitu 58 responden, dimana pada umumnya $62,1 \%$ tidak siap dalam implementasi pengurangan risiko bencana (PRB) dan 22 responden
$(37,9 \%)$ diantaranya siap dalam implementasi pengurangan risiko bencana (PRB)

Hasil uji Chi-sguare menunjukkan $p$ value sebesar 0.006 pada tingkat kemaknaan $5 \%$ ada hubungan yang significance antara mobilitas sumber daya terhadap kesiapsiagaan siswa dalam implementasi pengurangan risiko bencana (PRB) melalui pendidikan formal di SMA Negeri Unggul sigli dimana ( $p$ value $\leq$ $0,05)$.

Tabel 5. Hasil Analisis Bivariat

\begin{tabular}{llll}
\hline No & Variabel & p value & \multicolumn{1}{c}{ Kesimpulan } \\
\hline 1. & Pengetahuan dan Sikap & 0.022 & Ada hubungan yang siqnificance \\
\hline 2. & Rencana Tanggap Darurat & 0.002 & Ada hubungan yang siqnificance \\
\hline 3. & Sistim Peringatan Dini & 0.000 & Ada hubungan yang siqnificance \\
\hline 4. & Mobilitas Sumber Daya & 0.006 & Ada hubungan yang siqnificance \\
\hline
\end{tabular}

Sumber: Data primer Tahun 2020 
Berdasarkan table 5 resume hasil analisis bivariat di atas, dimana dari 4 variable independent yang diteliti yaitu pengetahuan dan sikap, rencana tanggap darurat, sistim peringatan dini dan mobilitas sumber daya. Hasil uji Chisquare menunjukan variabel yang sangat siqnificance secara statistik adalah variabel sistim peringatan dini terhadap kesiapsiagaan siswa dalam implementasi pengurangan risiko bencana (PRB) melalui pendidikan formal di SMA Negeri Unggul sigli Kecamatan Pidie

\section{Analisis Multivariat}

Tabel 6. Hasil analisis multivariat regresi logistik

\begin{tabular}{lccccc}
\multicolumn{1}{c}{ Variabel } & B & Df & Sig & Exp (B) & 95\% CI \\
\hline $\begin{array}{l}\text { Pengetahuan dan } \\
\text { Sikap }\end{array}$ & -802 & 1 & .091 & 4.48 & $1.77-11.37$ \\
\hline $\begin{array}{l}\text { Rencana Tanggap } \\
\text { Darurat }\end{array}$ & -725 & 1 & .144 & 4.84 & $1.83-12.82$ \\
\hline $\begin{array}{l}\text { Sistim Peringatan } \\
\text { Dini }\end{array}$ & -1.162 & 1 & .015 & 3.13 & $1.22-8.01$ \\
\hline $\begin{array}{l}\text { Mobilitas Sumber } \\
\text { Daya }\end{array}$ & -512 & 1 & .296 & 5.99 & $2.29-15.67$ \\
\hline Constant & 1.540 & 1 & .001 & 4.666 & \\
\hline
\end{tabular}

Sumber: Data primer Tahun 2020

Berdasarkan Tabel 6 hasil analisis multivariat regresi logistik ganda dari 4 variable independent diperoleh variabel yang paling dominan terhadap kesiapsiagaan siswa dalam implementasi pengurangan resiko bencana (PRB) adalah Variabel mobilitas sumber daya dengan koefisien B: -512 dan Exp (B) sebesar 5.99 artinya siswa yang mendapatkan mobilitas sumber daya dengan baik mempunyai peluang siap dalam implementasi pengurangan risiko bencana (PRB) 5.99 lebih besar dibandingkan dengan siswa yang mendapatkan mobilitas sumber daya tidak baik dalam implementasi pengurangan risiko bencana (PRB) melalui pendidikan formal di SMA Negeri Unggul sigli Kecamatan Pidie Kabupaten Pidie.

\section{PEMBAHASAN}

\section{Hubungan Pengetahuan dan Sikap Terhadap Kesiapsiagaan Siswa Dalam Implementasi PRB}

Berdasarkan hasil penelitian diketahui bahwa dari 104 reponden dengan proporsi pengetahuan dan sikap baik yaitu 69 responden, dimana pada umumnya yaitu $58,0 \%$ siap dalam implementasi pengurangan risiko bencana (PRB). Sedangkan proporsi pengetahuan dan sikap kurang yaitu 35 responden, dimana umumnya $65,7 \%$ tidak siap dalam implementasi pengurangan risiko bencana (PRB) dan 12 responden $(34,3 \%)$ siap dalam implementasi pengurangan risiko bencana (PRB). Hasil uji Chi-square menunjukkan $p$ value sebesar 0.022 pada tingkat kemaknaan 5\% ada hubungan yang significance antara pengetahuan dan sikap terhadap kesiapsiagaan siswa dalam implementasi pengurangan risiko bencana (PRB) dimana ( $p$ value $\leq 0,05)$. Hal ini berarti semakin baik pengetahuan dan sikap maka akan semakin tinggi kesiapsiagaan siswa dalam implementasi pengurangan resiko bencana (PRB).

Hasil tersebut sesuai dengan penelitian Ningtyas (2014) yang menyebutkan bahwa ada pengaruh positif pengetahuan kebencanaan terhadap sikap kesiapsiagaan warga dalam menghadapi bencana tanah longsor di Desa Sridadi Kecamatan Sirampog Kabupaten Brebes. dengan nilai 
$p$ value sebesar $(0.000<0,05)$. Pengetahuan kebencanaan akan dibutuhkan masyarakat yang tinggal di daerah rawan bencana, karena berbagai informasi mengenai jenis bencana yang mungkin mengancam mereka, gejala-gejala bencana, perkiraan daerah jangkauan bencana, prosedur penyelamatan diri, tempat yang disarankan untuk mengungsi, dan informasi lain yang mungkin dibutuhkan masyarakat pada sebelum, saat dan pasca bencana itu terjadi dapat meminimalkan risiko bencana (Mendikbud, 2015).

Hasil tersebut sesuai dengan penelitian Yulianto (2013) yang menyebutkan bahwa ada pengaruh yang signifikan antara pengetahuan dan sikap terhadap kesiapsiagaan siswa dalam menghadapi bencana banjir dan gempa bumi di SMP Negeri I Gatak Sukoharjo, dengan nilai $p$ value sebesar $(0.000<0,05)$. Hasil penelitian ini juga sejalan dengan penelitian yang dilakukan oleh Rinta (2020) yang menyatakan bahwa Ada hubungan yang signifikan antara pengetahuan siaga gempa bumi terhadap kesiapsiagaan diperoleh nilai (p-value $=0,000)$. Dan ada hubungan sikap siswa terhadap kesiapsiagaan diperoleh nilai ( $p$-value $=0,000$ ) yang menyimpulkan bahwa ada hubungan pengetahuan siaga gempa bumi dan sikap siswa terhadap kesiapsiagaan.

Keberhasilan mitigasi bencana merupakan salah satu ujian utama terhadap keberhasilan pendidikan yang diberikan dari generasi ke generasi. Pendidikan Pengurangan Risiko Bencana (PRB) merupakan sebuah kegiatan jangka panjang dan bagian dari pembangunan berkelanjutan. Melalui pendidikan diharapkan agar upaya pengurangan risiko bencana dapat mencapai sasaran yang lebih luas dan dapat dikenalkan secara lebih dini kepada seluruh peserta didik, dan pada akhirnya berkontribusi terhadap kesiapsiagaan individu maupun masyarakat terhadap bencana. Pendidikan Pencegahan dan Pengurangan Risiko Bencana dirancang untuk membangun budaya aman dan masyarakat yang tangguh (Suharwoto, $\mathrm{dkk}, 2015)$.

Hal tersebut diasumsikan karena pengetahuan yang dimiliki akan mempengaruhi sikap dan kepedulian seseorang/masyarakat untuk siap dan siaga dalam mengantisipasi bencana, terutama bagi mereka yang bertempat tinggal di daerah yang rentan terhadap bencana alam.

Hasil uji regresi logistik menunjukkan antara pengetahuan dan sikap terhadap kesiapsiagaan siswa dalam implementasi pengurangan risiko bencana (PRB). Dimana dengan koefisien B: -802 dan Exp (B) sebesar 4.48 artinya siswa yang mendapatkan pengetahuan dan sikap baik mempunyai peluang siap dalam implementasi pengurangan risiko bencana (PRB) 4.48 lebih besar dibandingkan dengan siswa yang mendapatkan pengetahuan dan sikap kurang dengan interval kepercayaan 1.77-11.37.

\section{Hubungan Rencana Tanggap Darurat Terhadap Kesiapsiagaan Siswa Dalam Implementasi PRB}

Berdasarkan hasil penelitian diketahui bahwa dari 104 reponden dengan proporsi rencana tanggap darurat baik yaitu 37 responden, dimana pada umumnya yaitu $70,3 \%$ siap dalam implementasi pengurangan risiko bencana (PRB). Sedangkan proporsi rencana tanggap darurat tidak baik yaitu 67 responden, dimana umumnya $61,2 \%$ tidak siap dalam implementasi pengurangan risiko bencana (PRB) dan 26 responden $(38,8 \%)$ siap dalam implementasi pengurangan risiko bencana (PRB). Hasil uji Chi-sguare menunjukkan $p$ value sebesar 0.002 pada tingkat kemaknaan 5\% ada hubungan yang significance antara rencana tanggap darurat terhadap kesiapsiagaan siswa dalam implementasi pengurangan risiko bencana (PRB) dimana ( $p$ value $\leq 0,05)$.

Hasil tersebut sesuai dengan penelitian Yulianto (2013) yang menyebutkan bahwa ada pengaruh yang signifikan antara rencana tanggap darurat terhadap kesiapsiagaan siswa dalam menghadapi 
bencana banjir dan gempa bumi di SMP Negeri I Gatak Sukoharjo, dengan nilai $p$ value sebesar $(0.000<0,05)$.

Penelitian ini juga sejalan dengan penelitian yang dilakukan oleh Ika (2019) yang menjelaskan bahwa kebijakan sekolah dalam kategori sedang dengan persentase $50 \%$, rencana tanggap darurat dalam kategori tinggi dengan persentase $66,7 \%$, dan, mobilisasi sumberdaya dalam kategori tinggi dengan persentase $66,67 \%$. Hal ini menunjukkan bahwa rencana tanggap darurat mempengaruhi terhadap kesiapsiagaan siswa dalam mengimplementasikan PRB.

Tanggap darurat merupakan serangkaian kegiatan yang dilakukan dengan segera pada saat kejadian bencana untuk menangani dampak buruk yang ditimbulkan, yang meliputi kegiatan penyelamatan dan evakuasi korban, harta benda, pemenuhan kebutuhan dasar, perlindungan, pengurusan pengungsi, penyelamatan, serta pemulihan prasarana dan sarana (emergency response) (UU No 24 tahun 2007).

Siswa memiliki persepsi yang berbeda dalam memaknai bencana. mereka sering digambarkan sebagai korban yang tidak berdaya dalam suatu keadaan darurat. Namun demikian, mereka dapat berkontribusi dalam upaya pemulihan, rehabilitasi dan rekonstruksi. (Erita dkk, 2019)

Penanggulangan bencana merupakan bagian integral dari pembangunan nasional, yaitu serangkaian kegiatan penanggulangan bencana sebelum, pada saat maupun sesudah terjadinya bencana. Seringkali bencana ditanggapi secara parsial oleh pemerintah. Bahkan bencana hanya ditanggapi dengan pendekatan tanggap darurat (emergency response) (Depkominfo,2007). Hal tersebut diasumsikan karena rencana tanggap darurat menjadi bagian yang penting dalam suatu proses kesiapsiargaaan, terutama yang terkait dengan evakuasi, pertolongan dan penyelamatan agar korban bencana dapat

diminimalkan

(ISDR/UNESCO,2006).

Hasil uji regresi logistik menunjukkan antara rencana tanggap darurat terhadap kesiapsiagaan siswa dalam implementasi pengurangan risiko bencana (PRB). Dimana dengan koefisien B: -725 dan Exp (B) sebesar 4.48 artinya siswa yang mendapatkan rencana tanggap darurat baik mempunyai peluang siap dalam implementasi pengurangan risiko bencana (PRB) 4.48 lebih besar dibandingkan dengan siswa yang mendapatkan rencana tanggap darurat dengan tidak baik dengan interval kepercayaan 1.83-12.82.

\section{Hubungan Sistim Peringatan Dini Terhadap Kesiapsiagaan Siswa Dalam Implementasi PRB}

Berdasarkan hasil penelitian diketahui bahwa dari 104 reponden dengan proporsi sistim peringatan dini baik yaitu 48 responden, dimana pada umumnya yaitu $70,8 \%$ siap dalam implementasi pengurangan risiko bencana (PRB). Sedangkan proporsi sistim peringatan dini tidak baik yaitu 56 responden, dimana umumnya $67,9 \%$ tidak siap dalam implementasi pengurangan risiko bencana (PRB) dan 18 responden $(32,1 \%)$ siap dalam implementasi pengurangan risiko bencana (PRB). Hasil uji Chi-sguare menunjukkan $p$ value sebesar 0.000 pada tingkat kemaknaan 5\% ada hubungan yang significance antara sistim peringatan dini terhadap kesiapsiagaan siswa dalam implementasi pengurangan risiko bencana (PRB) dimana ( $p$ value $\leq 0,05)$.

Hasil tersebut sesuai dengan penelitian Yulianto (2013) yang menyebutkan bahwa ada pengaruh yang significance antara sistim peringatan dini terhadap kesiapsiagaan siswa dalam menghadapi bencana banjir dan gempa bumi di SMP Negeri I Gatak Sukoharjo, dengan nilai $p$ value sebesar $\quad(0.000<0,05)$. Hasil penelitian ini juga sejalan dengan penelitian yang dilakukan oleh Hilman (2015) yang menyebutkan bahwa Terdapat hubungan yang bermakna dan sangat kuat antara self 
efficacy dan sistem peringatan dini dengan kesiapsiagaan bencana dengan nilai $P$ value sebesar (r 0,756; p 0,000).

Sistem peringatan bencana merupakan awal dari semua kesiapsiagaan yang dilakukan masyarakat, di mana sistem peringatan bencana yang baik akan membuat korban jiwa yang ditimbulkan akibat bencana berkurang atau ditekan sekecil mungkin (Mendikbud, 2015).

Hal tersebut diasumsikan karena sistem peringatan bencana merupakan awal dari semua kesiapsiagaan yang dilakukan masyarakat, di mana sistem peringatan bencana yang baik akan membuat korban jiwa yang ditimbulkan akibat bencana berkurang atau ditekan sekecil mungkin (Mendikbud, 2015).

Hasil uji regresi logistik menunjukkan antara sistim peringatan dini terhadap kesiapsiagaan siswa dalam implementasi pengurangan risiko bencana (PRB). Dimana dengan koefisien B: 1.162 dan Exp (B) sebesar 3.13 artinya siswa yang mendapatkan sistim peringatan dini baik mempunyai peluang siap dalam implementasi pengurangan risiko bencana (PRB) 3.13 lebih besar dibandingkan dengan siswa yang mendapatkan sistim peringatan dini tidak baik. dengan interval kepercayaan 1.22-8.01.

\section{Hubungan Mobilitas Sumber Daya Terhadap Kesiapsiagaan Siswa Dalam Implementasi PRB}

Berdasarkan hasil penelitian diketahui bahwa dari 104 reponden dengan proporsi mobilitas sumber daya baik yaitu 46 responden, dimana pada umumnya yaitu $65,2 \%$ siap dalam implementasi pengurangan risiko bencana (PRB). Sedangkan proporsi mobilita sumber daya tidak baik yaitu 58 responden, dimana umumnya $62,1 \%$ tidak siap dalam implementasi pengurangan risiko bencana (PRB) dan 22 responden $(37,9 \%)$ siap dalam implementasi pengurangan risiko bencana (PRB). Hasil uji Chi-sguare menunjukkan $p$ value sebesar 0.006 pada tingkat kemaknaan 5\% ada hubungan yang significance antara mobilitas sumber daya terhadap kesiapsiagaan siswa dalam implementasi pengurangan risiko bencana (PRB) dimana ( $p$ value $\leq 0,05)$.

Hasil tersebut sesuai dengan penelitian Yulianto (2013) yang menyebutkan bahwa ada pengaruh yang significance antara mobilitas sumber daya terhadap kesiapsiagaan siswa dalam menghadapi bencana banjir dan gempa bumi di SMP Negeri I Gatak Sukoharjo, dengan nilai $p$ value sebesar $(0.001<0,05)$. Penelitian ini juga sejalan dengan penelitian yang dilakukan oleh Ika (2019) yang menjelaskan bahwa mobilisasi sumberdaya dalam kategori tinggi dengan persentase $66,67 \%$ dan rencana tanggap darurat dalam kategori tinggi dengan persentase $66,7 \%$. Hal ini menunjukkan bahwa mobilisasi sumber daya mempengaruhi terhadap kesiapsiagaan siswa dalam mengimplementasikan PRB.

Mobilitas sumber daya didasarkan pada kemampuan guru dan staf dalam meningkatkan kesiapsiagaan menghadapi bencana. Sumber daya yang mendukung adalah salah satu indikator kesiapsiagaan yang mempertimbangkan bagaiman berbagi sumber daya yang ada digunakan untuk mengembalikan kondisi darurat akibat bencan menjadi kondisi normal (LIPI ISDR/UNESCO, 2006).

Hal tersebut diasumsikan karena sumber daya yang mendukung adalah salah satu indikator kesiapsiagaan yang mempertimbangkan bagaiman berbagi sumber daya yang ada digunakan untuk mengambalikan kondisi darurat akibat bencan menjadi kondisi normal (ISDR/UNESCO, 2006)

Hasil uji regresi logistik menunjukkan antara mobilitas sunber daya terhadap kesiapsiagaan siswa dalam implementasi pengurangan risiko bencana (PRB). Dimana dengan koefisien B: -512 dan Exp (B) sebesar 5.99 artinya siswa yang mendapatkan mobilitas sumber daya baik mempunyai peluang siap dalam implementasi pengurangan risiko bencana (PRB) 5.99 lebih besar dibandingkan 
dengan siswa yang mendapatkan mobilitas sunber daya tidak baik dengan interval kepercayaan 2.29-15.67.

\section{KESIMPULAN}

Ada hubungan pengetahuan dan sikap terhadap kesiapsiagaan siswa dalam implementasi pengurangan risiko bencana (PRB) dengan p.value 0,022. Diman semakin baik pengetahuan dan sikap, maka semakin tinggi kesiapsiagaan siswa dalam implementasi PRB . Ada hubungan rencana tanggap darurat terhadap kesiapsiagaan siswa dalam implementasi pengurangan risiko bencana (PRB) dengan $p$ value 0.002. Dimana semakin baik rencana tanggap darurat, maka semakin tingi kesiapsiagaan siswa dalam implementasi PRB.

Ada hubungan sistim peringatan dini terhadap kesiapsiagaan siswa dalam implementasi pengurangan risiko bencana (PRB) dengan $p$ value 0,000. Dimana semakin baik sistim peringatan dini, maka semakin tinggi kesiapsiagaan siswa dalam implementasi PRB. Ada hubungan mobilitas sumber daya terhadap kesiapsiagaan siswa dalam implementasi pengurangan risiko bencana (PRB) dengan $p$ value 0,006. Dimana semakin baik mobilitas sumber daya, maka semakin tinggi kesiapsiagaan siswa dalam implementasi PRB.

Variabel yang paling dominan terhadap kesiapsiagaan siswa dalam implementasi pengurangan risiko bencana (PRB) adalah variabel mobilitas sumber daya dimana dengan koefisien Exp (B) sebesar 5.99 dengan interval kepercayaan 2,29-15,67.

\section{UCAPAN TERIMAKASIH}

Dalam penelitian ini, peneliti banyak mendapatkan bantuan dari berbagai pihak. Sehubungan dengan hal tersebut peneliti mengucapkan terima kasih kepada Kepala Sekolah dan LPPM USM-INDONESIA.

\section{DAFTAR PUSTAKA}

BNPB Aceh Pergub No.51 Tahun 2011 Tentang Rencana Penanggulangan Bencana Aceh Tahun 2012-2017 diakse 07 Maret 2020.

BNPB. (2017). "Data Informasi Bencana Indonesia"(http://dibi.bnpb.go.id/dibi /), diakses tanggal 08 Maret 2020.

BNPB. (2020). Sebaran Kejadian Bencana 1 Januari 18 April. Jakarta

BPBA. (2019). Peraturan Gubernur Tentang Forum Pengurangan Resiko Bencana Aceh

Tribun Aceh (2020). Kejadian Bencana di Aceh Sejak Januari Hingga Maret 2020.

Bencana Kesehatan. ( 2014). "UNISDR Kritik Lemahnya Kebijakan Pencegahan dan Implementasi Program Pengurangan Bencana. Diakses 05 Februari 2020.

BPBD. (2019). Profil Badan Penanggulangan Bencana Daerah Kabupaten Pidie

Depkominfo. (2007). Tata Kelola Teknologi Informasi dan Komunikasi. Nasional, versi 1

Dewi,Liesnoor .(2019). Pendidikan Kebencanaan. Modul Universitas Negeri Semarang. Hlm.5.

Dinas Pendidikan. (2020). Jumlah Pendidikan SMA/Sederajat di Kabupaten Pidie

Erita, dkk. (2019). Modul pembelajaran Materi Pembelajaran Manajemen Gawat Darurat Dan Bencana . Universitas Kristen Indonesia.

Handini, M.C. (2018). Metodologi Penelitian Untuk Permula. Pustakapedia. Jakarta.

Ika, Nur. (2019). Implementasi Program Sekolah Siaga Bencana Di Smp Negeri Padureso Kabupaten Kebumen Tahun 2018. Universitas Negeri Semarang.

Kemendikbud. (2015). Pilar 3 Pendidikan Pencegahan Pengurangan Risiko Bencana. Biro Perencanaan dan Kerja Sama Luar Negeri. Jakarta. 
LIPI - UNESCO/ISDR. 2006. Kajian Kesiapsiagaan Masyarakat Dalam Mengantisipasi Bencana Gempa Bumi dan Tsunami. Jakarta.

Notoatmodjo. (2007). Metodologi Penelitian Kesehatan. Rineka Cipta. Jakarta

Ningtyas, B.A. (2014) Pengaruh Pengetahuan Kebencanaan Terhadap Sikap Kesiapsiagaan Warga dalam Menghadapi Bencana Tanah Lonsor di Desa Sridadi Kecamatan Sirapok Kabupaten Brebes.

Paripurno, E. T. \& Jannah. N M. (Eds) (2014). Panduan Pengelolaan Risiko Bencana Berbasis Komonitas $(P R B B K)$, PSMB-UPN. Jogjakarta.

Rancangan Qanun Aceh. (2019). Pendidikan Kebencanaan. Hlm 32.

Rahma, Aldila. (2018). "Implementasi Program Pengurangan Risiko Bencana (PRB)Melalui Pendidikan Formal". Jurnal Varia Pendidikan diakses 06 Februari 2020

Rencana Aksi Rehabilitasi dan Rekonstruksi Pascabencana Gempa Bumi, Kabupaten Pidie Jaya, Pidie dan Bireuen Provinsi Aceh Tahun 2017-2019.

Rinta, Tyas. (2020). Hubungan Pengetahuan Siaga Gempa Bumi dan Sikap Siswa terhadap Kesiapsiagaan di SD Negeri 2 Cepokosawit. Universitas Aisyiah Surakarta.
Rizaldy, David. (2018). "Implementasi Pendidikan Mitigasi Bencana di Sekolah-Sekolah di Indonesia Sebagai Upaya Pembentukan Karakter Siswa Siap Siaga", Prosiding PIT Ke-5 Riset Kebencanaan IABI Universitas Andalas, Padang 03 Maret 2020., hlm. 479-487.

Sastroasmoro, S., \& Ismael, S. (2016). Dasar-Dasar Metodologi Penelitian Klinis. Edisi.5. Sagung Seto. Jakarta.

Slameto, (2010). Belajar dan Faktor faktor yang Mempengaruhinya. Jakarta. Rineka Cipta.

Sugiyono, (2013) Metode Penelitian Pendidikan Pendekatan Kuantitatif, Kualitatif dan $R \& D$. Alfabeta Jakarta.

Suharwoto, dkk., (2015). "Modul 3. Pilar 3 - Pendidikan Pencegahan dan Pengurangan Risiko Bencana". Jakarta: Biro Perencanaan dan Kerjasama Luar Negeri Sekretariat Jendral Kemendikbud.

Supriyono, P, (2014). Seri Pendidikan Pengurangan Risiko Bencana Angin Puting Beliung. CV. Andi ofset. Yogyakartya.

Yulianto, M.I. (2013) Pengaruh Penggunaan Media pembelajaran Terhadap Kesiapsiagaan Siswa Dalamm Menghadapi Bencana Banjir dan Gempa Bumi di SMP Negeri I Gatak Sukoharjo. 